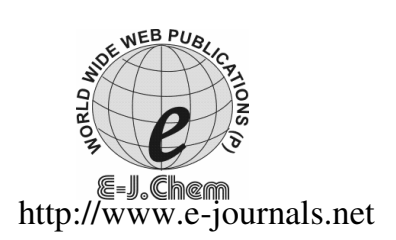

ISSN: 0973-4945; CODEN ECJHAO

E-Journal of Chemistry

2012, 9(1), 93-98

\title{
Determination of Mineral Elements of Some Coarse Grains by Microwave Digestion with Inductively Coupled Plasma Atomic Emission Spectrometry
}

\author{
LI YANG ${ }^{\S^{*}}$, QINGHUA YAN, YINPING CAO\# ${ }^{\#}$ and HUIRONG ZHANG ${ }^{\S}$
}

\author{
${ }^{\S}$ Department of Experimental Center \\ Henan Institute of Science and Technology, Xinxiang Henan 453003, P.R. China \\ Department of Life Science and Technology \\ Xinxiang Medical University, Xinxiang Henan 453003, P.R. China \\ ${ }^{\#}$ School of Science and Technology \\ Henan Institute of Science and Technology, Xinxiang Henan 453003, P.R. China
}

manyouhome1998@yahoo.cn

Received 24 May 2011; Accepted 31 July 2011

\begin{abstract}
To determinate the mineral elements contents in millet, maise, oat, buckwheat, sorghum and purple rice, microwave digestion procedure optimized was applied for digesting six coarse grains. Nineteen mineral element concentrations were determined by inductively coupled plasma atomic emission spectrometry (ICP-AES). Results displayed the limits of detection (LODs) and the limits of quantification (LOQs) range from 0.0047 to $0.1250 \mu \mathrm{g} / \mathrm{mL}$ and 0.0155 to $0.4125 \mu \mathrm{g} / \mathrm{mL}$. The relative standard deviations (RSDs) range from $0.83 \%$ to $5.03 \%$, which showed that this proposed method was accurate and precise to detect mineral elements in coarse grains simultaneously. Correlation coefficients (r) were calculated in the range of 0.999096-0.999989. The sufficient dada obtained described that the coarse grains selected were abundant in mineral element contents in the human body on daily diet. The success of combining the microwave digestion technology with the ICP-AES was a simple and precise method to determine many mineral elements in coarse grains simultaneously.
\end{abstract}

Keywords: Coarse grains, Mineral elements, Microwave digestion, ICP-AES

\section{Introduction}

A series of mineral elements, named biogenic, has a great importance for the living organisms ${ }^{1}$. Among these elements, some are known to be great important and essential for humans in a specific concentration range, like $\mathrm{Mn}, \mathrm{Cu}, \mathrm{Cr}, \mathrm{Co}$ and $\mathrm{Ni}$, however in higher 
concentration can be toxic to humans or in lower level may cause serious disorders of human body and functions ${ }^{2-5}$. Elements like $\mathrm{Cr}, \mathrm{Mn}, \mathrm{Zn}$ and $\mathrm{Cu}$ are usually found in the green plants but in low concentration, which does not affect the health of organisms from the food chain. Some of the trace elements are definitely toxicants, like $\mathrm{Cd}$ and $\mathrm{Pb}$. Dietary intake is the main route of exposure to mineral elements for most people. Thus information about mineral elements concentrations in food products and their dietary intake is very important for assessing their risk to human health ${ }^{6}$. At present, coarse grains have attracted more and more attention to common diet because they contain abundant beneficial components such as trace elements. Among these products, millet, maise, oat, buckwheat, sorghum and purple rice are the most popular agricultural products consumed for medical purposes or maintaining good health ${ }^{7}$.

Inductively coupled plasma atomic emission spectrometry (ICP-AES) presents distinct advantages when compared with other instrumental techniques, due to the wide coverage of determinable elements, the power of detection and the excellent precision and accuracy attainable with modern instruments of high resolution ${ }^{8}$. In contrast to conventional flame AAS or Electrothermal atomic absorption spectrometry, the high-energy ICP-AES allows the simultaneous recording of different spectral lines, which enables multi-elements analysis of a single sample. Further, the dynamic range is several folds greater ${ }^{9}$.

Millet, maise, oat, buckwheat, sorghum and purple rice are six kinds of essential coarse grains in northern China, so determining and comparing contents of mineral elements in these coarse grains are very meaning for human health. In this work, microwave digestion method of sample preparation for determination of a range of mineral elements in coarse grains samples was proposed. $\mathrm{HNO}_{3}$ and $\mathrm{H}_{2} \mathrm{O}_{2}$ were used as extractants. Element concentrations were measured by ICP-AES.

\section{Experimental}

MAS microwave digestion system (CEM Corporation of USA), Optima2100 DV inductively coupled plasma atomic emission spectrometry (ICP-AES, PerkinElmer Corporation of USA).

The operational parameters of the microwave digestion: powder: $800 \mathrm{~W}$, ramp: $120{ }^{\circ} \mathrm{C}$ for $6 \mathrm{~min}$, hold for $6 \mathrm{~min}$; powder: $1600 \mathrm{~W}$, ramp: $160{ }^{\circ} \mathrm{C}$ for $5 \mathrm{~min}$, hold for $12 \mathrm{~min}$; powder: $1600 \mathrm{~W}$, ramp: $200{ }^{\circ} \mathrm{C}$ for $8 \mathrm{~min}$, hold for $18 \mathrm{~min}$. Working conditions of ICPAES: RF Power: $1.3 \mathrm{kw}$; Auxilary gas flow rate (Ar): $0.2 \mathrm{~L} / \mathrm{min}$; Cooling gas flow (Ar): 15.0 L/min; Carrier gas flow (Ar): $0.6 \mathrm{~L} / \mathrm{min}$.

\section{Material}

The coarse grains samples of millet, maise, oat, buckwheat, sorghum and purple rice were bought from the agricultural product market in Xinxiang, China and authenticated by Doc. Benguo Liu (School of Food Science, Henan Institute of Science and Technology, Xinxiang, China).

\section{Reagents and standard solutions}

$\mathrm{HNO}_{3}$ (superior grade of pure, Zhengzhou Piney Chemical Reagent Factory), $\mathrm{KH}_{2} \mathrm{PO}_{4}$. $\mathrm{H}_{2} \mathrm{SO}_{4}, \mathrm{H}_{2} \mathrm{O}_{2}$ (analysis grade of pure, Shenzhen Yongsheng Chemical Co., Ltd.). An Ultrapure water system (SG Ultra Clear system, Wasseraufbereitung und Regenerierstation $\mathrm{GmbH}$, Germany) was used to produce ultra pure water with specific conductivity down to $0.055 \mu \mathrm{S} / \mathrm{cm}$ for the analysis of ICP-AES. 
Mixed standard stock solution: concentration of $\mathrm{Na}, \mathrm{K}, \mathrm{Cu}, \mathrm{Fe}, \mathrm{Zn}, \mathrm{Mn}, \mathrm{Ca}, \mathrm{Mg}, \mathrm{Al}, \mathrm{Se}$, $\mathrm{B}, \mathrm{Be}$ and $\mathrm{Ba}$ were all $1000 \mu \mathrm{g} / \mathrm{mL}, \mathrm{Cr}, \mathrm{Pb}, \mathrm{Ni}$, As and $\mathrm{Cd}$ were all $100 \mu \mathrm{g} / \mathrm{mL}$ (Merck of Germany).

$50 \mathrm{mg} / \mathrm{L} \mathrm{P}$ standard stock solution: $0.2195 \mathrm{~g}$ of $\mathrm{KH}_{2} \mathrm{PO}_{4}$ baked at $105{ }^{\circ} \mathrm{C}$ for $2 \mathrm{~h}$ were accurately weighed into deionized water of $400 \mathrm{~mL}$ and $5.0 \mathrm{~mL}$ concentrated $\mathrm{H}_{2} \mathrm{SO}_{4}$ were added (prevent mould growing). At last, the mixture solution were transferred to $1000 \mathrm{~mL}$ volumetric flasks and made up to $1000 \mathrm{~mL}$ with deionized water.

$0.5,1.00,2.00,4.00$ and $8.00 \mu \mathrm{g} / \mathrm{mL}$ mixed standard solutions of $\mathrm{Na}, \mathrm{K}, \mathrm{Cu}, \mathrm{Fe}, \mathrm{Zn}$, $\mathrm{Mn}, \mathrm{Ca}, \mathrm{Mg}, \mathrm{Al}, \mathrm{Se}, \mathrm{B}, \mathrm{Be}$ and $\mathrm{Ba}$ were prepared by diluting $1000 \mu \mathrm{g} / \mathrm{mL}$ mixed standard stock solutions with $2 \%$ nitric acid. $0.25,0.5,1.00,2.00$ and $4.00 \mu \mathrm{g} / \mathrm{mL}$ mixed standard solutions of $\mathrm{Cr}, \mathrm{Pb}, \mathrm{Ni}$, As and $\mathrm{Cd}$ were prepared by diluting $100 \mu \mathrm{g} / \mathrm{mL}$ mixed standard stock solution with $2 \%$ nitric acid. 5.00, 10.00, 15.0025 .00 and $50.00 \mu \mathrm{g} / \mathrm{mL}$ standard solutions of $\mathrm{P}$ were prepared by diluting $50 \mathrm{mg} / \mathrm{L} \mathrm{P}$ standard stock solution with $2 \%$ nitric acid.

\section{Sample handling and determination}

The different coarse grains were washed with deionized water and were baked in oven at $80{ }^{\circ} \mathrm{C}$ for $6 \mathrm{~h}$. Then, all samples were smashed using high speed universal grinder and the sample powders were obtained. A $0.30 \mathrm{~g}$ sample powders was weighed into a PTFE vessel and $9 \mathrm{~mL}$ of concentrated $\mathrm{HNO}_{3}$ and $2 \mathrm{~mL}$ of $30 \% \mathrm{H}_{2} \mathrm{O}_{2}$ were added. Six parallel samples were digested simultaneously with the optimized microwave digestion system. When the digestion program finished, a twenty-minute ventilation step (no microwave power) cooled the vessels for reducing the pressure inside to ambient values. After digestion, the solution was evaporated to dryness on an electric heating board at $170{ }^{\circ} \mathrm{C}$. The residue was dissoluted by $3 \mathrm{~mL}$ of $5 \% \mathrm{HNO}_{3}$ and was transferred into a volumetric flask and made up to $50 \mathrm{~mL}$ with ultrapure water. Blank solutions were prepared in the same way as the samples. Concentrations of mineral elements in coarse grains were determined with ICP-AES.

\section{Results and Discussion}

\section{Selection of optimum spectral lines}

One of the problems concerning ICP-AES is spectral interferences caused by matrix elements. The interference free determination was investigated for each element by recording the spectra of the sample solution and potentially interfering elements near the analytical line. Each analyte element was determined in three spectral lines by ICP-AES. The criteria for the selected spectral lines were the sensitivity. Much more spectral lines represent unexceptionably characteristics and they could be used for the estimation of the samples. For $\mathrm{Cu}, \mathrm{Fe}, \mathrm{Zn}, \mathrm{Mn}, \mathrm{Na}, \mathrm{K}, \mathrm{Ca}, \mathrm{Mg}, \mathrm{Al}, \mathrm{Se}, \mathrm{B}, \mathrm{Be}, \mathrm{Ba}, \mathrm{Ni}, \mathrm{As}, \mathrm{Cd}$ and $\mathrm{P}$ spectral line at $324.75,259.93,213.85,257.61,589.59,766.49,317.93,279.07,396.18,196.02$, 249.69, 313.06, 455.42, 231.60, 193.69, 193.69 and 213.63 nm was selected as optimum since they showed the highest sensitivity among others, respectively. For $\mathrm{Cr}$, spectral line at $267.716 \mathrm{~nm}$ was selected as optimum even if it was showed a bit lower sensitivity than line $283.563 \mathrm{~nm}$, because the latter showed lower reproducibility on samples. For the same reason the spectral line $220.35 \mathrm{~nm}$ instead of $261.41 \mathrm{~nm}$ was selected for $\mathrm{Pb}$.

\section{Sample digestion}

Most atomic spectrometric methods require introduction of dissolved samples into the atomizer. The basic digestion procedure involves the addition of suitable reagents (e.g. acids, oxidation agents) to the sample and enough energy to decompose organic molecules 
or to destroy the crystalline structure of minerals ${ }^{10-12}$. Biological samples consist mainly of organic components which are normally digested with oxidizing agents at as high temperatures as possible. An increase of the temperature leads to a higher degree of digestion efficiency in a shorter time and a low residual carbon content. An efficient decomposition of sample without losses of volatile elements is critical for total recovery of elements. In the research, microwave digestion procedure with sealed digestion vessels is increasingly being used for digestion of biological samples for element analysis. As to digestion solution, if only nitric acid is used, some samples, are not digested completely and the digestion solution is turbid. The use of microwave digestion with the addition of a mixture of nitric acid and hydrogen peroxide $(\mathrm{V} / \mathrm{V}=9 / 2)$ for the digestion of samples in this study was found to be efficient and rapid. The digested solution obtained was clear and no solid residues were observed in the solution.

\section{Detection linearity, regression equation and correlation coefficients}

Calibration curves were obtained for analysis elements using a series of multi-element calibration standard solutions. Limit of detection (LOD) is defined as the lowest concentration level that is statistically different from a blank ( $\mathrm{LOD}=3 \mathrm{SD} / \mathrm{m}$; $\mathrm{m}$ is the slope of the addition graph, SD is the within-run standard deviation of single blank determination), corresponding to a $99 \%$ confidence level. Similarly, limit of quantification (LOQ) is defined as $\mathrm{LOD}=10 \mathrm{SD} / \mathrm{m}$, the level above which quantitative results can be obtained with $99 \%$ confidence level. A good linear relationship between the corresponding sensitivities and the concentrations of the analysis elements was achieved. The calculated regression equation, correlation coefficients (r), LOD and LOQ by ICP-AES method were showed in Table 1.

Table 1. Calibrations and detection limits of the elements by ICP-AES

\begin{tabular}{ccccc}
\hline Element & Regression equation & $\begin{array}{c}\text { Correlation } \\
\text { coefficient }(\mathrm{r})\end{array}$ & $\begin{array}{c}\text { LOD, } \\
\mu \mathrm{g} / \mathrm{mL}\end{array}$ & $\begin{array}{c}\text { LOQ, } \\
\mu \mathrm{g} / \mathrm{mL}\end{array}$ \\
\hline $\mathrm{Cu}$ & $\mathrm{Y}=47523 \mathrm{X}+1625.6$ & 0.999987 & 0.0082 & 0.0271 \\
$\mathrm{Fe}$ & $\mathrm{Y}=170542 \mathrm{X}+1552.9$ & 0.999989 & 0.0098 & 0.0323 \\
$\mathrm{Zn}$ & $\mathrm{Y}=156241 \mathrm{X}+264.9$ & 0.999961 & 0.0083 & 0.0274 \\
$\mathrm{Mn}$ & $\mathrm{Y}=184128 \mathrm{X}+5087.3$ & 0.999950 & 0.0047 & 0.0155 \\
$\mathrm{Na}$ & $\mathrm{Y}=2099765 \mathrm{X}-19290$ & 0.999301 & 0.0987 & 0.3257 \\
$\mathrm{~K}$ & $\mathrm{Y}=756674 \mathrm{X}-74375.9$ & 0.999096 & 0.0724 & 0.2389 \\
$\mathrm{Ca}$ & $\mathrm{Y}=20392 \mathrm{X}+9842.1$ & 0.999298 & 0.0529 & 0.1746 \\
$\mathrm{Mg}$ & $\mathrm{Y}=2792 \mathrm{X}+142.1$ & 0.999984 & 0.0512 & 0.1690 \\
$\mathrm{Al}$ & $\mathrm{Y}=23568 \mathrm{X}+413.8$ & 0.999961 & 0.0768 & 0.2534 \\
$\mathrm{Se}$ & $\mathrm{Y}=1189 \mathrm{X}+72.1$ & 0.999365 & 0.1250 & 0.4125 \\
$\mathrm{~B}$ & $\mathrm{Y}=92874 \mathrm{X}+1187.2$ & 0.999969 & 0.0185 & 0.0611 \\
$\mathrm{Be}$ & $\mathrm{Y}=3408642 \mathrm{X}+35982.4$ & 0.999102 & 0.0073 & 0.0241 \\
$\mathrm{Ba}$ & $\mathrm{Y}=218188776 \mathrm{X}-119786.2$ & 0.999989 & 0.0053 & 0.0175 \\
$\mathrm{Cr}$ & $\mathrm{Y}=27177 \mathrm{X}+239.4$ & 0.999991 & 0.0137 & 0.0452 \\
$\mathrm{~Pb}$ & $\mathrm{Y}=4837 \mathrm{X}+52.7$ & 0.999911 & 0.0821 & 0.2709 \\
$\mathrm{Ni}$ & $\mathrm{Y}=27486 \mathrm{X}+187.1$ & 0.999937 & 0.0217 & 0.0716 \\
$\mathrm{As}$ & $\mathrm{Y}=762.1 \mathrm{X}+4.5$ & 0.999635 & 0.0920 & 0.3036 \\
$\mathrm{Cd}$ & $\mathrm{Y}=61913 \mathrm{X}+2784.7$ & 0.999899 & 0.0183 & 0.0604 \\
$\mathrm{P}$ & $\mathrm{Y}=6413 \mathrm{X}+2405.8$ & 0.999798 & 0.0993 & 0.3277 \\
\hline
\end{tabular}




\section{Precision and accuracy}

For this research, the recovery test was done in order to demonstrate the validity of the whole analytical procedure. The percentage recovery lies within the range 90.83-104.31\% (with RSD 0.83-4.03\%) for all elements in millet (Table 2) which confirms that the method is of good precision and accuracy. The precision of the analytical method was evaluated in terms of relative standard deviation (RSD) of the six measured values of each element in millet. The RSD were found to be $<5 \%$, which indicate that the precision of the analytical method is good.

Table 2. Accuracy and recovery of determination method, $\mu \mathrm{g} / \mathrm{mL}(\mathrm{n}=6)$

\begin{tabular}{cccccc}
\hline Element & Base value & RSD \% & Quantity added & Quantity found & Recovery $\%$ \\
\hline $\mathrm{Cu}$ & 6.76 & 3.81 & 5 & 11.62 & 97.27 \\
$\mathrm{Fe}$ & 35.42 & 1.83 & 10 & 45.29 & 98.71 \\
$\mathrm{Zn}$ & 26.18 & 0.83 & 10 & 36.27 & 100.87 \\
$\mathrm{Mn}$ & 6.22 & 1.04 & 5 & 11.19 & 99.48 \\
$\mathrm{Na}$ & 118.97 & 1.77 & 50 & 168.56 & 99.17 \\
$\mathrm{~K}$ & 1245.05 & 2.86 & 200 & 1442.79 & 98.87 \\
$\mathrm{Ca}$ & 308.20 & 2.68 & 200 & 503.68 & 97.74 \\
$\mathrm{Mg}$ & 562.25 & 2.96 & 200 & 758.05 & 97.90 \\
$\mathrm{Al}$ & 11.80 & 3.74 & 10 & 21.48 & 96.81 \\
$\mathrm{Se}$ & 3.50 & 1.79 & 2 & 5.33 & 91.53 \\
$\mathrm{~B}$ & 7.90 & 1.88 & 5 & 13.05 & 102.91 \\
$\mathrm{Be}$ & 3.06 & 1.94 & 2 & 5.13 & 103.48 \\
$\mathrm{Ba}$ & 1.33 & 2.49 & 1 & 2.37 & 104.31 \\
$\mathrm{Cr}$ & 0.98 & 3.80 & 1 & 2.01 & 103.42 \\
$\mathrm{~Pb}$ & 3.65 & 4.03 & 2 & 5.75 & 104.89 \\
$\mathrm{Ni}$ & 0.59 & 1.92 & 0.5 & 1.07 & 96.18 \\
$\mathrm{As}$ & 5.33 & 3.92 & 5 & 9.87 & 90.83 \\
$\mathrm{Cd}$ & $\mathrm{ND}$ & 2.86 & 0.5 & 0.49 & 97.81 \\
$\mathrm{P}$ & 1520.25 & 1.64 & 200 & 1727.63 & 103.69 \\
\hline
\end{tabular}

\section{Contents of mineral elements in six coarse grains}

Plants constitute important components of ecosystems as they provide the transport pathway from the abiotic to biotic environment. Uptake of elements by plants reflects their bioavailability in soils and affects plant yield and crop quality to the extent that animal or human health may be jeopardized ${ }^{13}$. The mineral element contents of six kinds of coarse grains were presented in Table 3. The results indicated that all these six kinds of coarse grains from Xinxiang market were found with $\mathrm{Na}, \mathrm{K}, \mathrm{Cu}, \mathrm{Fe}, \mathrm{Zn}, \mathrm{Mn}, \mathrm{Ca}, \mathrm{Mg}, \mathrm{Al}, \mathrm{Se}, \mathrm{B}, \mathrm{Be}, \mathrm{Cr}$ and $\mathrm{P}$. Might be due to growth conditions and geographical variations, some heavy metal elements were detected in some coarse grains, such as $\mathrm{Pb}, \mathrm{Ba}$, As. Ni was not found in corn, sorghum and purple rice. $\mathrm{Cd}$ was not found in all coarse grains. $\mathrm{Cu}, \mathrm{Mn}, \mathrm{K}, \mathrm{Mg}, \mathrm{B}, \mathrm{Be}$ and $\mathrm{P}$ were found to be higher in buckwheat relative to other kinds of coarse grains. $\mathrm{Zn}$ and As content was the high in maise. $\mathrm{Fe}, \mathrm{Na}, \mathrm{Ca}, \mathrm{Se}, \mathrm{Ba}$ and $\mathrm{Ni}$ were higher in oat. $\mathrm{Al}$ and $\mathrm{Cr}$ were found to be high in sorghum. $\mathrm{Pb}$ content was high in purple rice. From a human nutritional point of view, we should take in more coarse grains, such as purple rice and oat on daily diet. 
Table 3. Contents of mineral element in different coarse grains, $\mu \mathrm{g} / \mathrm{g}(\mathrm{n}=6)$

\begin{tabular}{ccccccc}
\hline Element & Millet & Maise & Oat & Buckwheat & Sorghum & Purple rice \\
\hline $\mathrm{Cu}$ & 6.76 & 3.55 & 9.08 & 11.08 & 5.83 & 8.00 \\
$\mathrm{Fe}$ & 35.42 & 10.57 & 91.08 & 43.91 & 35.58 & 25.50 \\
$\mathrm{Zn}$ & 26.18 & 195.65 & 34.58 & 29.66 & 8.58 & 21.08 \\
$\mathrm{Mn}$ & 6.22 & 1.01 & 51.91 & 13.91 & 4.83 & 13.25 \\
$\mathrm{Na}$ & 118.97 & 151.48 & 250.41 & 218.16 & 183.75 & 175.83 \\
$\mathrm{~K}$ & 1245.05 & 738.14 & 4262.50 & 5925.00 & 1383.33 & 1926.66 \\
$\mathrm{Ca}$ & 308.20 & 187.05 & 1075.00 & 514.66 & 203.75 & 349.50 \\
$\mathrm{Mg}$ & 562.25 & 105.83 & 1792.50 & 2940.00 & 531.58 & 1191.66 \\
$\mathrm{Al}$ & 11.80 & 11.70 & 30.91 & 28.75 & 49.25 & 13.66 \\
$\mathrm{Se}$ & 3.50 & 3.95 & 8.16 & 7.33 & 4.50 & 6.41 \\
$\mathrm{~B}$ & 7.90 & 5.48 & 19.16 & 21.91 & 17.33 & 7.58 \\
$\mathrm{Be}$ & 3.06 & 3.01 & 4.75 & 4.83 & 4.58 & 4.66 \\
$\mathrm{Ba}$ & 1.33 & 0.98 & 5.25 & 1.75 & 1.66 & 2.00 \\
$\mathrm{Cr}$ & 0.98 & 0.59 & 1.33 & 1.25 & 1.92 & 1.33 \\
$\mathrm{~Pb}$ & 3.65 & 4.59 & 6.66 & 6.08 & 5.66 & 6.91 \\
$\mathrm{Ni}$ & 0.59 & $\mathrm{ND}$ & 3.66 & 0.41 & $\mathrm{ND}$ & $\mathrm{ND}$ \\
$\mathrm{As}$ & 5.33 & 6.52 & 1.75 & 4.00 & 1.25 & 1.16 \\
$\mathrm{Cd}$ & $\mathrm{ND}$ & $\mathrm{ND}$ & ND & ND & ND & ND \\
$\mathrm{P}$ & 1520.25 & 530.63 & 4562.50 & 4723.33 & 1200.00 & 2924.16 \\
\hline \multicolumn{7}{c}{ ND: not detected } \\
\hline
\end{tabular}

\section{Conclusion}

The microwave assisted extraction applied here are found to be a convenient, rapid and reproducible sample preparation method for the direct determination of mineral elements in powdered plant samples by the ICP-AES method. ICP-AES is simple and precise method to determine many mineral elements in coarse grains simultaneously. From a human nutritional point of view, buckwheat was the rich in mineral element such as $\mathrm{Cu}, \mathrm{Mn}, \mathrm{K}, \mathrm{Mg}, \mathrm{B}, \mathrm{Be}$ and $\mathrm{P}$. Oat contain relatively large amounts of $\mathrm{Fe}, \mathrm{Na}, \mathrm{Ca}, \mathrm{Se}, \mathrm{Ba}$ and $\mathrm{Ni}$.

\section{References}

1. Carmen C E, Irina D, Gabriela B and Nicoleta S I, Environ Sci Pollut Res., 2010, 17(6), 1230-1236.

2. Pomazal K, Prohaska C and Steffan I, J Chromatogr A, 2002, 960, 143-150.

3. Todorovska N, Karadjova I and Stafilov T, Anal Bioanal Chem., 2002, 373, 310-313.

4. Alimonti A, Petrucci F, Santucci B, Cristaudo A and Caroli S, Anal Chim Acta, 1995, 306, 35-41.

5. Qinghua Y, LI Y, Liyuan N and Huigen F, Asian J Chem., 2011, 23(10), 4689-4693.

6. Zhuang P, McBride B B, Xia H P, Li N Y and Li Z A, Sci. Total Environ., 2009, 407(5), 1551-1561.

7. Li R, Huang X L and Jiang Z T, Eur Food Res Technol., 2008, 227(1), 111-116.

8. Garavaglia R N, Rebagliati R J, Roberti M J and Batistoni D A, Spectrochim Acta Part B., 2002, 57(12), 1925-1938.

9. Rahil-Khazen R, Henriksen H, Bolann B J and Ulvik R J, Scand J Clin Lab Invest., 2000, 60(8), 677-786.

10. Bocca B, Alimonti A, Forte G, Petrucci F, Pirola C, Senofonte O and Violante N, Anal Bioanal Chem., 2003, 377(1), 65-70.

11. Bian Q Z, Jacob P, Berndt H and Niemax K, Anal Chim Acta, 2005, 538, 323-329.

12. Riondato J, Venhaecke F, Moens L and Dams R, J Anal At Spectrom., 1997, 12, 933.

13. Mingorance M D, Anal Bioanal Chem., 2002, 373,153-158. 


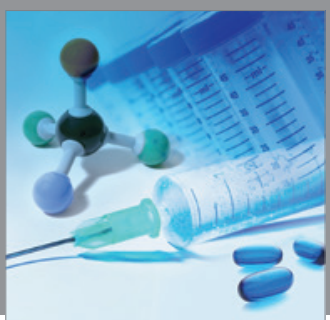

International Journal of

Medicinal Chemistry

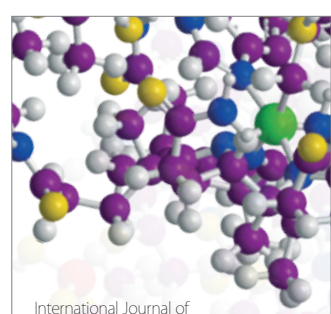

Carbohydrate Chemistry

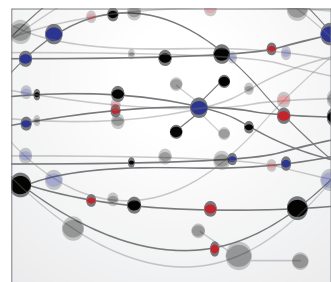

The Scientific World Journal
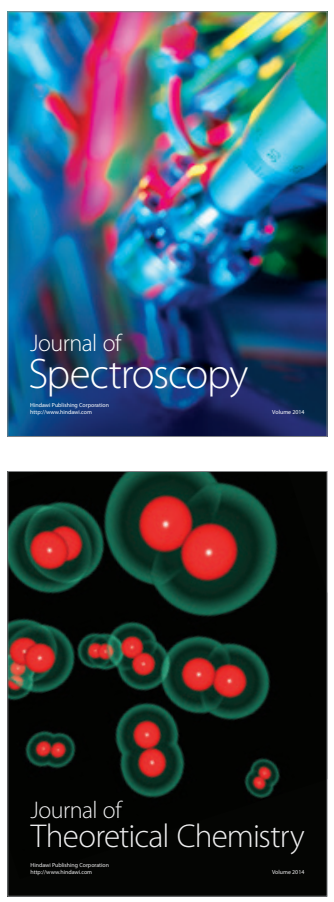
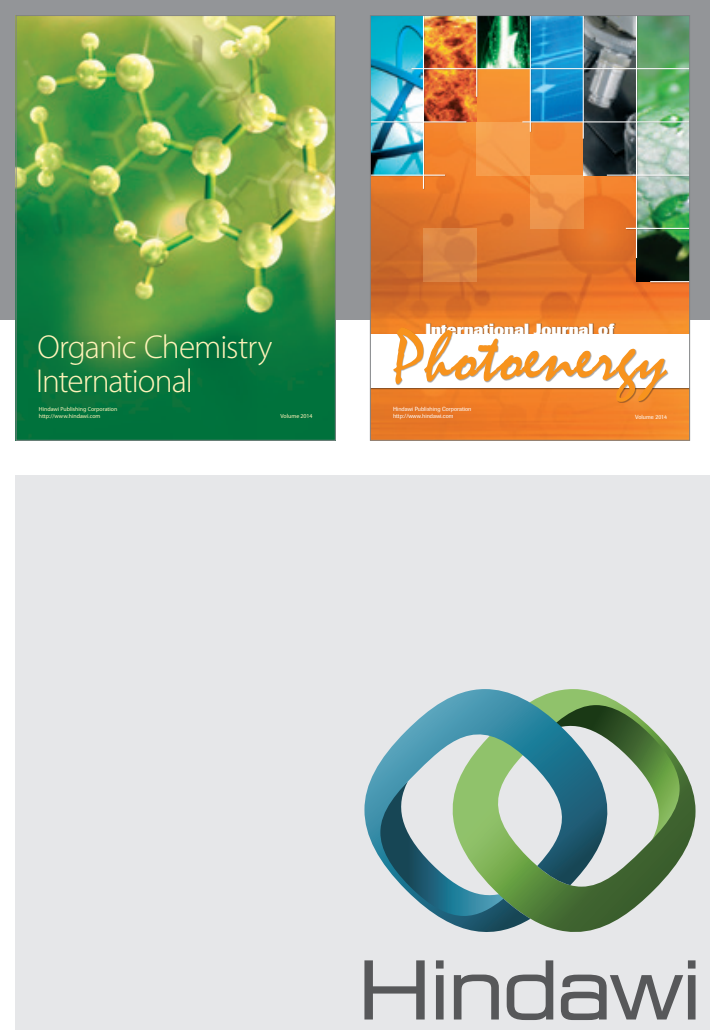

Submit your manuscripts at

http://www.hindawi.com
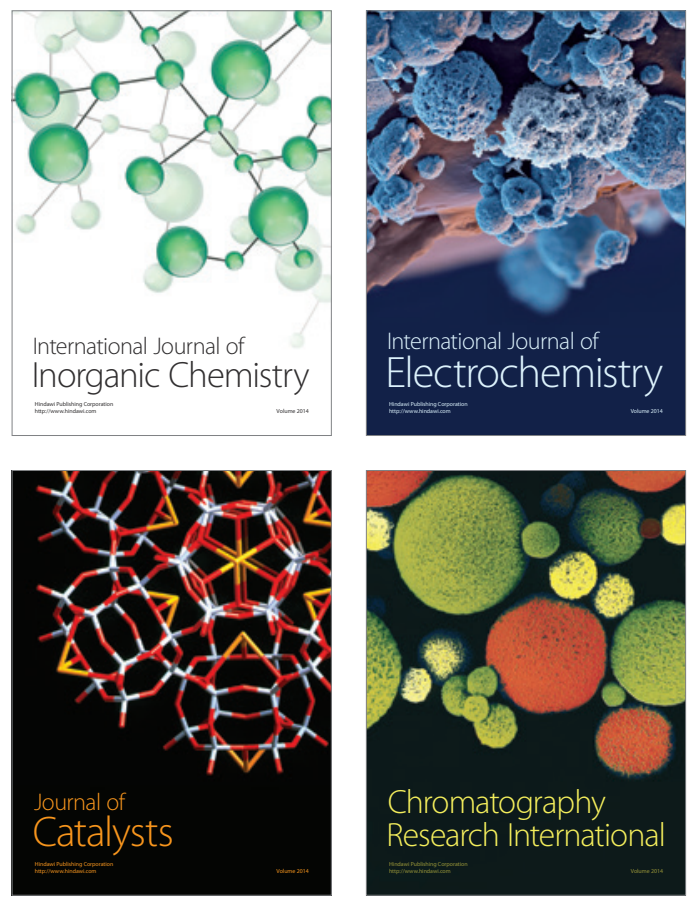
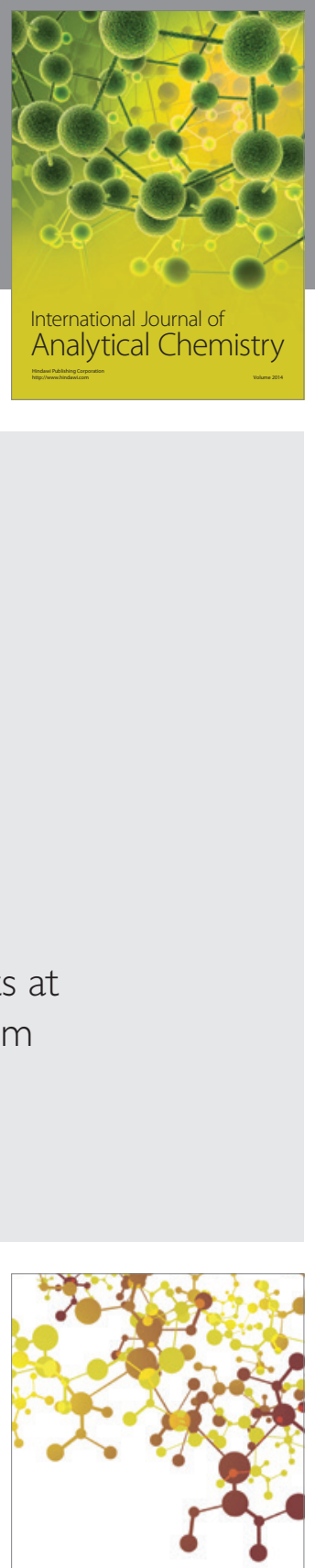

Journal of

Applied Chemistry
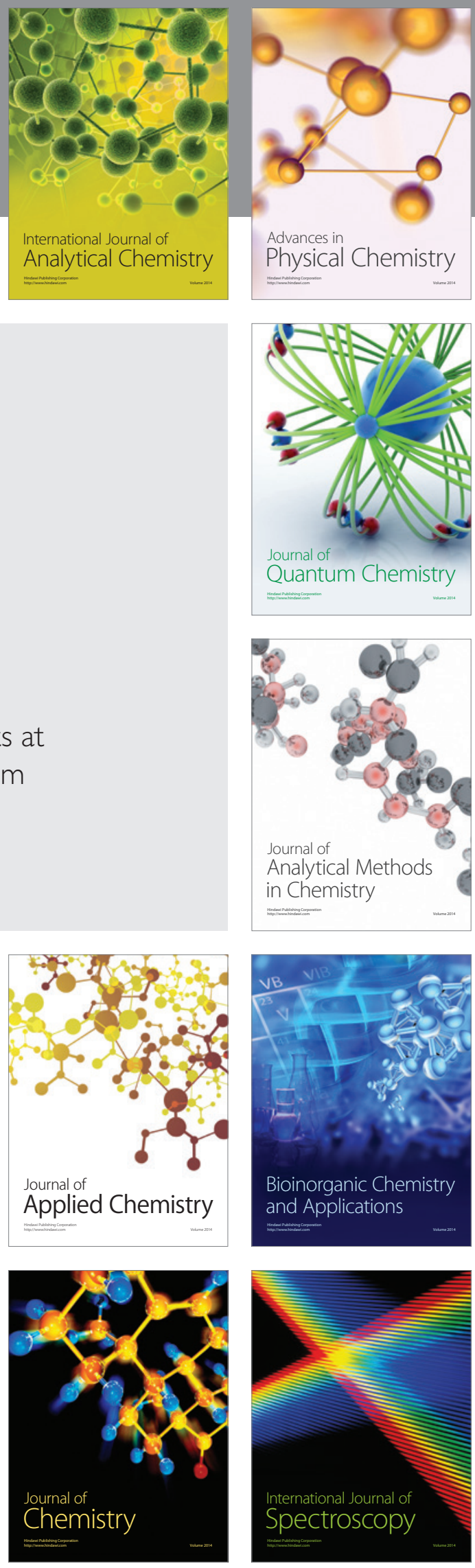